\title{
Organizational learning-COVID-19 experience: innovative global practices for improving patient care in crisis response
}

\author{
Jamie Muskopf ${ }^{1}$, Nimit Sudan ${ }^{2}$, Elise Verdooner $^{3}$, Murali Nair $^{3}$ \\ ${ }^{1}$ Columbia University School of Professional Studies, New York, NY, USA; ${ }^{2}$ University of California at Los Angeles School of Medicine, Los \\ Angeles, CA USA; ${ }^{3}$ Columbia University School of Social Work, New York, NY, USA \\ Contributions: (I) Concept and design: J Muskopf; (II) Administrative support: J Muskopf; (III) Provision of study materials or patients: N Sudan, E \\ Verdooner, M Nair; (IV) Collection and assembly of data: J Muskopf; (V) Data analysis and interpretation: All authors; (VI) Manuscript writing: All \\ authors; (VII) Final approval of manuscript: All authors. \\ Correspondence to: Jamie Muskopf, DSW. Associate, School of Professional Studies, New York, NY, USA. Email: jamie.muskopf@columbia.edu.
}

\begin{abstract}
Across human history, civilizations have responded to disasters and outbreaks of disease with increasingly complex, systematic approaches as a means of organizing chaos and protecting human life. The SARS-CoV-2 coronavirus (COVID-19) pandemic provides a unique opportunity to learn from the practice of disaster management and crisis-driven changes to patient care processes in hospital and emergent care environments worldwide. COVID-19 acts as an accelerant for process change and the need for redesign in systems where classical, linear evaluation methods most often inform carefully implemented service improvements. Strikingly, many innovative approaches and valuable lessons come from all over the globe where technology and access to resources have been most limited. This article answers the question, what can we learn about how to respond to future disasters from the evolution of disaster management as performed by helping professionals and policymakers during the past hundred-plus years and best practices seen today? Macro practitioners have co-created unique approaches within several global communities to help cope with COVID-19 and other disasters despite limited resources and seemingly unlimited needs. Referencing existing case studies of patient care responses during COVID-19 in Italy, Nigeria, South Africa, South Korea, and the United States, the authors document innovative practices and use of diverse technologies in local patient care systems. The article concludes by suggesting best practices for designing more robust, adaptive, and crisis ready responses to patient care, as well as the use of developmental evaluation as an agile approach to evaluating and improving patient services. It also suggests roles that helping professionals can play in the translation of big data systems of disaster management from organizations such as the Center for Disease Control, World Health Organization, non-governmental organizations (NGOs), and selected think tanks, among others.
\end{abstract}

Keywords: COVID-19; disaster management; innovation; developmental evaluation; organizational learning

Received: 20 October 2020; Accepted: 02 March 2021; Published: 25 June 2021.

doi: 10.21037/jhmhp-21-19

View this article at: http://dx.doi.org/10.21037/jhmhp-21-19

\section{Introduction}

The argument has often been made that progress leads to a more civilized society-that civilization allows humans to progress, both as a species and as individuals (1). Still, some argue civilization comes at an unsustainable cost attributed to the limitations of urbanization, competent government, social organization, and allocation of resources and human wellbeing. Outbreaks of disease have always threatened humanity and posed a challenge to civility. In the 1600s, smallpox decimated the indigenous peoples of North America. The yellow fever epidemic swept through the Caribbean Islands in the 1700s severely impacting their populations. In the 1800 s, Cholera began as a pandemic 
in India and quickly spread through trade routes. As civilization evolves, an imperative emerges to understand how the evolution of such disasters threaten humanity on a global scale.

For the greater part of 2020 and all of 2021, SARSCoV-2 coronavirus (COVID-19) has dominated the global consciousness, having profound impact on every aspect of modern civilization. More than 110 million cases have been confirmed and over two million deaths attributed to COVID-19 worldwide with the spread showing inconsistent signs of slowing. While humankind has survived its share of pandemics, never has it done so at a time of such great technological advancement when information has been so easy to disseminate rapidly and widely. World leaders and the public at large have relied heavily upon the scientific community to make sense of the unknown and combat disinformation by communicating up-to-the-minute findings about COVID-19 prevention, spread, treatment, and vaccine development.

Emergency response teams and medical service providers across the world have reacted and adapted swiftly to new safety requirements in emergent and non-emergent patient care settings. As more becomes known about effective responses in patient care during the pandemic, pivots that have been documented in case studies can guide our understanding not only of how to improve patient care during disaster, but how to redesign patient care systems in ways that both inform and comply with laws and public health policies. Further, these lessons will inform the use of innovative technologies, processes, and evaluation methods, and identify how to address patient needs as the situation continues to evolve.

This article aims to answer the question, what can we learn about how to respond to future disasters from the evolution of disaster management as performed by helping professionals and policymakers during the past hundred-plus years and best practices seen today among organizations, countries, health care providers, and helping professionals? It provides a brief history of disaster management, reviews several of the most recent case studies highlighting innovative practices in response to COVID-19 around the world, identifies how technology has been leveraged to improve and innovate around patient care, and it concludes with recommendations for organizations and decision makers focused on redesigning patient care systems as they prepare for future emergencies and the unknown extenuating impacts of the current pandemic.

\section{Methods}

\section{Search strategy}

Electronic searches were conducted to find case studies addressing COVID-19 related patient care responses published in English in peer-reviewed publications from the period of March 2020 to October 2020. A separate series of searches were conducted to construct a history of global disaster management. The search strategy included four categories of terms: "COVID-19", "disaster management", "organizational learning", "innovation" and related synonyms.

\section{Study selection process}

The authors-a cadre of scholars in medicine, social work, international development, and technology—screened titles, abstracts, and full texts of all search results based on the inclusion criteria in their respective portions of the research. All authors screened the titles and abstracts of articles considered and, in some cases, developed annotated bibliographies for review. One reviewer screened the cases mentioned to assess them for eligibility of inclusion in this article.

\section{Inclusion criteria}

To be included in this review, materials must have provided context in the areas of disaster management, technology in health care, and examples of patient care during COVID-19. Case studies must have included reactive approaches to addressing patient care during COVID-19 and a summary of outcomes.

\section{Assessing risk of bias in included studies}

The reviewers did their best to eliminate bias by explicitly seeking case studies showing innovative practices outside of the United States, highlighting cases from Asia, Europe, and Africa. As COVID-19 remains a developing situation, selection was based primarily on availability of written, peer reviewed case studies with an effort to include those that best documented changes to patient care practices in response to the pandemic.

\section{Results}

\section{A bistory of disaster management}

Emergency management and preparedness have been 
a reactive science historically. The industry's evolution resulted from catastrophes, calamities, heightened risks, and newly identified threats that affect the population, economic stability, infrastructure, and national resilience. Below is a sampling of key events that advanced emergency management and/or disaster response efforts (2).

\section{Union Fire Company [1736]}

On a quest to improve firefighting techniques, Benjamin Franklin organized and led this volunteer fire department to be a city-wide model of firefighting best practices.

\section{Congressional Act of 1803}

One of the first examples of the United States Federal government proactively addressing a local disaster. The Act enabled the government to provide assistance to a New Hampshire town after an extensive fire.

\section{American Red Cross [1881]}

Clarissa Harlowe Barton founded the volunteer organization, which has grown into one of the world's largest volunteer networks. The organization promotes a cooperative effort to protect and enhance lives of individuals in the wake of personal and large-scale disasters.

\section{Flood Control Act [1917]}

Floods on the Mississippi, Ohio, and other rivers in the northeast led to the Flood Control Act of 1917, the first act aimed exclusively at controlling floods. In 1934, a version of the legislation increased the authority of the Army Corps of Engineers to design and build flood control projects.

\section{Reconstruction Finance Corporation (RFC)}

On January 22, 1932, the U.S. Congress established and authorized the agency to originate disaster loans for repair and reconstruction of certain public facilities following an earthquake, and later, other types of disasters. The 1953 RFC Liquidation Act terminated its lending powers in an effort to fulfill President Dwight Eisenhower's vision of limiting government's involvement in the economy. By 1957 , its remaining functions had been transferred to other agencies.

\section{Bureau of Public Road}

In 1934, the agency was given the authority to provide funding for highways and bridges damaged by natural disasters.

\section{Disaster Relief Act of 1950}

Authorized the President of the United States to issue disaster declarations. As a result, the declaration permitted federal agencies to provide direct assistance to state and local governments in the wake of a disaster.

\section{Federal Civil Defense Act of 1950}

The threat of nuclear war and its subsequent radioactive fallout precipitated numerous defense legislations. The Act provided the basic preparedness framework to minimize the effects of an attack on the civilian population and a plan to respond to the immediate emergency conditions created by the attack.

\section{Office of Emergency Preparedness [1960]}

As a result of a series of disasters (Hurricane Donna, Hurricane Carla, and a 7.3 Montana earthquake) the Kennedy administration established this agency to oversee the seemingly growing risk of natural disasters.

\section{National Flood Insurance Act of 1968}

The legislation was prompted by the unavailability or prohibitively expensive flood insurance coverage. The Act resulted in the National Flood Insurance Program (NFIP).

\section{Federal Emergency Management Agency (FEMA)}

By 1970, over 100 federal agencies and thousands of state and local entities were involved in risk management and disaster response efforts. The scattered, fragmented, and decentralized concept led to duplicated efforts, confusion, and political power struggles. FEMA was created to centralize efforts and minimize disorder.

\section{Oil Pollution Act of 1990 (OPA90)}

In the wake of the Exxon Valdez oil spill, the law created comprehensive prevention, response, liability, and compensation policies for vessels and facilities that could cause oil pollution to U.S. navigable waters.

\section{Federal Response Plan [1992]}

The plan aimed to provide a systematic process and structure for coordinated delivery of Federal assistance to address the effects of any major disaster or emergency declared under the Robert T. Stafford Disaster Relief and Emergency Assistance Act.

\section{September 11, 2001}

FEMA activates the Federal Response Plan as a response 
to the worst terrorist attack on the United States. The attacks can be identified as one of history's turning points for the rapid advancement and coordination of emergency management.

\section{Homeland Security Act of 2002}

Was established as a result of the September 11, 2001 attacks in effort to protect the United States from further terrorist attacks, reduce the nation's vulnerability to terrorism, and minimize the damage from potential terrorist attacks and natural disasters.

\section{National Response Plan [2004]}

Developed out of the need to implement common incident management and response principles. The NRP replaced the Federal Response Plan.

\section{National Response Framework [2008]}

Through stakeholder feedback, a series of disasters, and subsequent lessons learned, the framework was developed to enhance the principles of the National Response Plan. The changes incorporated the concept that an effective incident response is a shared responsibility of all levels of governments, the private sector and non-governmental organizations (NGOs), and individual citizens.

In an effort to understand the evolution of disease, frameworks can be applied to assess a crisis in a systematized environment (3). The framework is an overview of a multisystem environment that analyzes how human, environmental, and technological systems interact with one another. It is also imperative to acknowledge developing countries experience the greatest challenges from infectious diseases attributed to malnutrition, poor sanitation, poor water quality and inadequate health care. As civilization advances, sustainability and morbidity should be considered.

As civilization has progressed, disease outbreaks have been a common problem for humanity. Although times have changed, there are common problems that arise from disaster and outbreaks that continue to threaten many lives. From the Indian Ocean Tsunami to the Spanish Flu in the early 1900s, there are common lessons that may be applied (4). Mass deaths are attributed to shortages of supplies and personnel and there has always been a generated demand for volunteers, globally. Economic problems and impact on vulnerable populations have affected the containment of disasters. Furthermore, historic mass deaths have resulted in planning and experience acquired that may be useful in planning for future pandemics (4).

A pandemic narrative may be described as a failure to contain attributed to lack of health care capacity, shortages of supplies, and coordination with multidisciplinary agencies (5). With civilization, humanity has experienced the emergence of diseases that threaten populations globally. Human demographics and behavior as well as swift population growth and urbanization are attributes of morbid public health epidemics. Spread of infectious diseases may be attributed to changes in human behavior, lifestyles, land use, trade and travel, and inappropriate use of health care (6).

Advances in infectious diseases occurred in the 1900s that resulted after World War 1 and after the Second World War. Malaria, smallpox, venereal disease, tuberculosis and polio rapidly spread during those times. Lethal communicable diseases continued to arise through the 1980s that include cholera, HIV, Ebola, hepatitis C, Nipah virus, and influenza. Global epidemics continue to spread and involve mass deaths today (2). Common issues continue to be overlooked in public health crises (7). Procedural decision-making, substantial prioritization of ethical, political, and logistical concerns, and affective human concerns should be incorporated in public health emergency protocols, guidelines, and training (7).

Throughout the years, there are lessons learned as a response to public health epidemics and pandemics. Inadequate coordination and funding at the international and national level significantly hinder capacity and supplies. Lack of capacity and funding create a gap between socioeconomic levels and poor countries and determine availability of access and quality healthcare. There has always been an inadequate emphasis on demographic and socioeconomic challenges threatening vulnerable populations (8). Furthermore, improvements in health care and collaboration with multidisciplinary professionals promote socioeconomic parity and an ecological perspective that promotes equitable patient preventative care (9).

\section{Responses to COVID-19}

Much of what is known about pandemics is learned from studying past responses, and in the case of COVID-19, researchers Eaton \& Kalichman looked to the HIV literature to study the social and behavioral health responses (10). The researchers discussed how frameworks learned through HIV prevention and treatment are necessary to understanding better responses to 
COVID-19 now. This includes studying the interpersonal factors that stymied HIV prevention and treatment, including barriers to accessing support, medical mistrust, social stigmas, social marginalization, and structural disparities (9). Understanding these challenges in the case of HIV responses can help indicate the challenges and successes in development and mobilization of COVID-19 responses.

Across the globe, governments are responding to the COVID-19 pandemic: international borders closed, emergency planning and action underway, and discussions of a "new normal" are taking place. Literature is emerging on the countries hardest hit by the pandemic, illuminating the vulnerabilities and the fragility of these systems. Aggressive and early response to disease management have proven effective in some countries. And countries with focused mitigation and prevention strategies already in place for such an event have seen few cases and are proactively responding to the spread of this deadly disease. Three case studies are presented from countries across three continents and focus on their response to the COVID-19 pandemic. The cases of Italy, the country with the oldest population in Europe; Nigeria, the country with the largest population in Africa; and South Korea, among the first countries where the virus spread, will provide examples of COVID-19 patient care process change across the world.

While much of the world continues to battle COVID-19, these examples can provide initial assessment on efficient prevention methods. As with many countries in the world, Italy, Nigeria and South Korea experienced a significant increase in the number of COVID-19 cases in late 2020 and early 2021 . And while Italy remains one of the countries with the highest total number of cases, Nigeria and South Korea are experiencing few new cases relative to their population. Varying factors affecting these outcomes should be considered, such as demographic, sociodemographic, geopolitical, political, and environmental determinants. Based on the trend of COVID-19 cases in these countries, an initial assessment suggests that aggressive and adaptive testing and tracking and comprehensive multisectoral and intergovernmental collaboration as seen in Nigeria and South Korea have been highly effective in curbing the spread of the pandemic.

\section{Italy}

There are many lessons we may learn from Italy's experience with the pandemic, including effective decision- making strategies, healthcare support for patients, and cohesive isolation mandates. The experience of scarce equipment, hospital capacity, and health care providers becoming ill challenged Italy, known for having one of the most efficient health care systems and oldest populations in the world. Italy was faced with having to decide who would receive treatment based on survival probability (11). Due to the large number of older people, nursing homes became high-risk locations and the country ensured to protect their most vulnerable population by avoiding contact with family members to reduce the risk (12).

However, the rapid spread was caused by other factors that include misinformation about the risks and spread, the delay of social isolation restrictions, and the management of probable cases (12). Two of the wealthiest regions, Lombardy and Veneto, experienced the spread of the disease in varying degrees, with Lombardy experiencing rapid expansion of the virus (13). Although social distancing was enforced in both regions, Veneto's actions were more comprehensive, including testing of symptomatic and asymptomatic people, testing of neighbors where families in home isolation tested positive, and the immediate monitoring and protection of essential workers (12). In addition, Veneto enforced home care during the early and mild stages of the virus, decreasing the impact on hospital capacity and exposure of health care professionals (12).

Italy's experience with COVID-19 helped highlight challenges but also provide opportunities to address changes to these implications (14). An area of focus was the need for public services to protect and care for people. The Italian Ministry of Health hired "community nurses and social workers" as an effort to enhance "specialised treatment for patients at home" and to connect with communities and improve health and reduce inequalities (15). It is of critical importance to shift our attention toward action that translates into practice of social change and social justice (15).

\section{Nigeria}

The first case recorded in Nigeria was imported from Italy in late February 2020. Unlike the United States and Brazil with record numbers of cases, Nigeria was able to slow the spread of the disease through social and medical responses on a multisectoral level. After the World Health Organization declared COVID-19 a public health emergency on January 30, 2020, Nigeria created the Coronavirus Preparedness Group on January 31, 2020. The 
Nigerian Centre for Disease Control (NCDC) activated a National Emergency Operations Centre (EOC) to manage national incidence coordination centers; the Presidential Task Force (PTF) was created March 7, 2020 to coordinate Nigeria's governmental efforts (16); and travel restrictions and mandated self-isolation periods were enforced (17). The organization and success of Nigeria's response can partially be attributed to the prevention techniques in place as a result of the 2014 Ebola Virus Disease outbreak in West Africa. Nigeria capitalized on innovative solutions to address the deadly disease and prevent widespread infection. The Emergency Operations Center utilized an Incident Management System (IMS) to "coordinate the response and consolidate decision making, [which] is largely credited with helping contain the Nigeria outbreak early" (18).

As COVID-19 spread within Nigeria and the death rate increased, the NCDC and government departments took active steps towards rethinking how patients received treatment. The Lagos State Government created Eko Telemedicine in an effort to provide healthcare services not related to COVID-19 (19). Beyond utilizing telemedicine, the NCDC provides public health education and updates on the outbreak and preventative measures that can be taken, disseminated on social media and through broadcasting.

The lack of protective equipment for healthcare workers and shortage of health facilities and equipment could devastate Nigeria's population and healthcare system if COVID-19 is not successfully repressed. The protection of Nigerians from greater life loss due to COVID-19 is dependent on their "multisectoral coordination and proactiveness" (17).

\section{South Korea}

South Korea quickly gained international media presence shortly after COVID-19 left China's borders and began spreading across the globe. South Korea became a model for the rest of the world in demonstrating the benefits of rapid response and aggressive contract tracing. The behavioral response of citizens and swift governmental action in COVID-19 times could be attributed to lessons learned from the Middle East respiratory syndrome (MERS) outbreak in 2015, which resulted in severe population damage, government distrust, and societal stress (20-22). As one of the first few countries where the virus began spreading, South Korea can provide an example of efficient use of information technology and an adaptive approach to policymaking and crisis response.
At the start of the spread of COVID-19, advanced information technology systems were developed and utilized by the government for tracing, which led to significant decreases of new cases only two months after the first reported case (22). Koreans in quarantine were required to report on an app their health status, aggregated location data, as well as reporting individuals they have been in contact with who may also be exposed. While these measures have come under scrutiny for privacy concerns, the rapid response helped flatten the curve in March, with nationwide deaths under 500 compared to the United States' which has over 200,000 deaths (23).

The containment of COVID-19 in South Korea can be attributed to an agile and adaptive approach, increased government transparency, and citizen cooperation (21). Where some countries embraced herd immunity and others a stricter approach with curfews and lockdowns, South Korea's "agile-adaptive approach" focused on proactively identifying new and potential cases and adjusting to data and feedback from the field rather than on based on political calculations (21). The sizable number of tests and tracking allowed the government to gain greater understanding of the disease and how best to respond. They embraced innovative approaches to minimize infections spread in hospitals by creating drive- and walk-through testing facilities (21).

\section{Systems responses to COVID-19}

Health care systems across the world have implemented numerous changes in their processes due to the COVID-19 pandemic. This includes preparation of hospitals to handle surge of patients, trying to contain and prevent the spread of the infection, and introduction of new treatment strategies. Many immediate changes were implemented at the beginning of the COVID-19 pandemic including limiting nonessential medical services.

In South Africa, a decision was made to de-escalate surgical care (24). Non-essential surgical procedures were cancelled or reduced. Many hospitals repurposed operating rooms as ventilated critical care beds and reallocated surgical staff to other services such as COVID-19 testing, intensive care unit (ICU) and emergency department (ED) (24). Triage practices have also been adapted to the pandemic and new triage workflows were quickly established. EDs set up tents as triage centers to evaluate patients as they arrived (25). Patients are now greeted by clinical staff wearing personal protective equipment (PPE). 
Initially, many patients were being evaluated and tested in their vehicles, many sent home if they did not require hospitalization. Sub-waiting rooms have been established to isolate patients with respiratory symptoms. If COVID-19 infection was suspected, patients were triaged directly to airborne respiratory contact isolation rooms. Hospitals have converted and designated units specifically dedicated to COVID-19 patients (25).

Inpatient services had to adapt specifically to handle the surge of patients. In New York, some hospitals saw nearly a $50 \%$ surge over maximum in their census (26). A large majority of admitted were COVID-19 positive and many required ICU care. Adaptations to handle this volume included redefining staff prioritization, expanding capacity of isolation rooms and ICU beds, utilizing technology such as video visits to communicate with hospitalized patients, and stockpiling equipment such as ventilators, medications and PPEs (26-28). Inpatient units were specifically converted and designated as COVID-19 units. Hospitals had to create workflow algorithms for management of situations that have never existed before, such as drug and equipment shortages.

Significant changes have been instituted to make medical organizations safe for business by preventing and limiting the spread of infection. A number of guidelines have been developed by various medical societies. American Society of Clinical Oncology (ASCO) suggests for cancer patients to self-isolate and minimize activities outside the home (29). These also include minimizing hospital and outpatients visits. Hospitals and outpatient clinics were suggested to use PPE, to screen patients and staff for symptoms and temperature prior to entering, limit family visitations, sanitizing the environment, and quarantining staff and patients with exposure and symptoms $(28,30)$.

\section{Discussion}

\section{Pandemic public health norms illuminate inequity}

Despite the varied responses to COVID-19 at institutional and governmental levels, four prevention recommendations have become commonly promoted public health practices across the globe. They include mask wearing, keeping a physical distance of six feet or more, handwashing, and limiting in-person social gatherings. While these appear simple in their approaches, their simplicity also helps to illuminate how access to proper protective resources, clean water, and the ability for those in low-income and marginalized communities to maintain physical distance are not universally achievable.

Structural and institutional racism in health care systems has been well-documented, and the marginalization of migrant communities perpetuate differential outcomes in health (31). The poor, homeless and other marginalized communities, including communities of color, have been systematically left behind as those with better resources are able to access the latest in biomedical advances (31). Lack of access to safe sanitation and water insecurity undermine a basic pillar of COVID-19 prevention in many parts of the world with twenty-nine percent of the global population living without safely managed drinking water and three billion people without access to soap or water for handwashing at home (31).

A statistical correlation of a Physical Distancing Readiness Index exists to the incidence rate and case fatality ratio of COVID-19. In particular, there is a disproportionality of the capacity of poor households to observe social distancing and adhere to lockdowns, leading to an increase in infection rates (32). Addressing public health implications and prioritizing policy and planning measures post-COVID to ensure the health of everyone. This includes addressing huge deficits such as accessibility to clean drinking water, toilet facilities, clean environment and living conditions, electricity, and access to health information to minimize health and social implications (32). Inequities may be disrupted by noting many people are "deprived of earning and income but also live in dense habitations with poor access to water and sanitation, creating barriers to hand washing, maintaining hygiene and observing physical distance" to prevent the implications of the pandemic (32).

\section{Technology is not enough}

New strategies had to be instituted to manage patients under care for other ailments and chronic illnesses, both in outpatient and inpatient settings. These included risk minimizations, care prioritization, health care team management, and applying new technology $(26,27,29,33)$. One major change has been to institute Telehealth and COVID-19 pandemic has accelerated its advancement significantly, maybe by a decade. Telehealth with video visits is not a new innovation and has been possible for decades but it has failed to be widely accepted. Prior to the pandemic, there was a traditional, long standing assumption that all medical care had to be in person. Telemedicine 
is actually quicker, easier, more convenient and safer for patients. Payment had been the principal barrier for its wide adoption, as most insurances have not conventionally provided coverage. Since the COVID pandemic, almost overnight, by necessity, virtually every healthcare provider can now deliver care utilizing telemedicine. Medicare paved the way for providers to allow billing for virtual visits in March 2020 (33). Private payers have since followed. Some estimate that up to $25 \%$ of all medical visits are now video visits. In Nigeria, Eko Telemedicine has prioritized nonemergency healthcare issues not related to COVID-19, allowing Nigerian residents to address their health needs without traveling to the doctor and risking exposure. Italy is deploying community workers to care for patients in their homes; and South Korea is utilizing app-based technology for contact tracing. Adaptive measures are being taken worldwide to ensure continued access to healthcare. Despite acceptance of these new technologies, there are still some limitations. For example, doctors cannot examine patients thoroughly by a video visit. Many companies are working on this specific issue.

Another barrier is patient access to appropriate devices and good broadband connections. Even more fundamental is that some patients, particularly the elderly, lack the technological skills needed to connect. As in the case of Italy, community-based care combined with technologybased solutions could be effective in patient care.

\section{The role of helping professions in disaster management}

Social workers have played a significant role in the containment of disease outbreaks. There is great opportunity for social work to be promoted further in public health and natural disaster and emergency planning. Social workers have been essential in addressing the social and economic consequences of disease outbreaks and in response to systems that influence public health and wellbeing (34). The social work profession upholds ethics, skills, and practice that uphold human rights, address inequality of access to treatment, and disrupt unequal and devastating attributes to death rates (35).

In 1918, the role of social work in health care was established as hospital social workers responded to the needs of World War I (36). The influenza pandemic and epidemics of tuberculosis and venereal disease provided an opportunity for social workers to meet the demanding needs in health care and society. During that time, social workers formed professional organizations, published two journals, and expanded opportunities for professional education (36).

A rapid change in the field of social work was to move from meeting needs individually from acute care to a community-based focus and to highlight how individuals can actively participate in their own health care decisions. The new approach is attributed to the ethics and values of the profession of social work, which were first established in 1960 by the National Association of Social Workers (37) as an effort to define the values and principles that guide social workers to meet the needs of individuals and society.

Jane Adams' campaign for public health began as a fight for proper sanitation to address the needs of vulnerable communities in Chicago (38). Adams saw a need to reform sanitation concerns to ensure people in Chicago had a chance at good health and living conditions. During that time, industries contributed to pollution in cities, factories produced poisonous chemicals into the city air, and the meatpacking industry produced waste and clogged waterways that were attributed to excessive garbage, rats, and insects (34). The emerging public health crisis was the result of the industrial revolution. Throughout the 1900s, modernization, industrialization, and urbanization caused American cities to deal with public health crises that resulted from overcrowded living conditions, dangerous workspaces, and unsanitary conditions in the environment.

\section{Conclusions}

Those looking for best patient care practices during COVID-19 must seek examples from every area of the world, but particularly countries that addressed patient care issues successfully without the benefit of technology or sophisticated health care systems to support them. Equity and equitable access issues should be at the forefront of these considerations.

Patient care providers will need to prepare for future surges and expand capacity. To do this they should plan for the conversion of units to dedicated COVID-19 units, use ED triage, stockpile equipment to the best of their abilities, and redefine staff prioritization by determining how they will use staff for screening and testing in and out in COVID-19 units.

Providers should minimize risk by screening all staff and patients and creating new workflows to prevent the spread among staff that includes staff screening, adequate PPE supply, handwashing, and social distancing.

Telehealth and following CDC guidelines for COVID-19 management should be fully incorporated into management of non-emergent care. 
Health care systems should consider developmental evaluation and equitable evaluation frameworks as an approach to validating and iterating innovative patient care processes in complex patient care environments.

\section{Recommended websites}

Centers for Disease Control and Prevention: Coronavirus (COVID-19). Available online: https://www.cdc.gov/ coronavirus/2019-ncov/index.html

U.S. Department of Homeland Security FEMA: Coronavirus (COVID-19) Response. Available online: https://www.fema.gov/disasters/coronavirus

U.S. Department of Homeland Security FEMA: Coronavirus Emergency Management Best Practices. Available online: https://www.fema.gov/disasters/ coronavirus/best-practices

World Health Organization (WHO): Coronavirus disease (COVID-19 pandemic. Available online: https:// www.who.int/emergencies/diseases/novel-coronavirus-2019

University of Oxford Research: Covid-19. Available online: https://www.ox.ac.uk/research/support-researchers/ covid-19?wssl=1

Harvard University: Coronavirus. Available online: https://www.hsph.harvard.edu/coronavirus/covid-19research-and-information-from-around-the-school/

\section{Acknowledgments}

The authors wish to thank our partners, families, and communities for their support during these extraordinarily challenging times.

Funding: None.

\section{Footnote}

Provenance and Peer Review: This article was commissioned by the Guest Editors (Erick Guerrero and Jemima A. Frimpong) for the series "Organizational Approaches to Implement Rapid Change in Hospitals to Respond to Public Health Emergencies" published in Fournal of Hospital Management and Health Policy. The article has undergone external peer review.

Peer Review File: Available at http://dx.doi.org/10.21037/ jhmhp-21-19

Conflicts of Interest: All authors have completed the ICMJE uniform disclosure form (available at http://dx.doi. org/10.21037/jhmhp-21-19). The series "Organizational Approaches to Implement Rapid Change in Hospitals to Respond to Public Health Emergencies" was commissioned by the editorial office without any funding or sponsorship. The authors have no other conflicts of interest to declare.

Ethical Statement: The authors are accountable for all aspects of the work in ensuring that questions related to the accuracy or integrity of any part of the work are appropriately investigated and resolved.

Open Access Statement: This is an Open Access article distributed in accordance with the Creative Commons Attribution-NonCommercial-NoDerivs 4.0 International License (CC BY-NC-ND 4.0), which permits the noncommercial replication and distribution of the article with the strict proviso that no changes or edits are made and the original work is properly cited (including links to both the formal publication through the relevant DOI and the license). See: https://creativecommons.org/licenses/by-nc-nd/4.0/.

\section{References}

1. Bowden B. The Thin Ice of Civilization. Alternatives: Global, Local, Political 2011;36:118-35.

2. World Health Organization. (n.d.). Disease Outbreaks. Available online: https://www.who.int/emergencies/ diseases/en/

3. Chen C, Neal D, Neal D, et al. Understanding the evolution of a disaster-a Framework for Assessing Crisis in a System Environment (FACSE). Natural Hazards 2013;65:407-22.

4. Scanlon J, McMahon T, Van Haastert C. Handling Mass Death by Integrating the Management of Disasters and Pandemics: Lessons from the Indian Ocean Tsunami, the Spanish Flu and Other Incidents. Journal of Contingencies and Crisis Management 2007;15:80-94.

5. Gerlach NA. From Outbreak to Pandemic Narrative: Reading Newspaper Coverage of the 2014 Ebola Epidemic. Canadian Journal of Communication 2016;41:611.

6. Gannon, J. Global Infectious Disease Threat and Its Implications for the United States. Central Intelligence Agency; 2000.

7. Kayman H, Logar T. A Framework for Training Public Health Practitioners in Crisis Decision-Making. Disaster Med Public Health Prep 2016;10:165-73. 
8. Rosoff PM. The Ethics of Care: Social Workers in an Influenza Pandemic. Soc Work Health Care 2008;47:49-59.

9. Black B, Bruce ME. Treating Tuberculosis: The Essential Role of Social Work. Soc Work Health Care 1998;26:51-68.

10. Eaton LA, Kalichman SC. Social and behavioral health responses to COVID-19: lessons learned from four decades of an HIV pandemic. J Behav Med 2020;43:341-5.

11. Rosenbaum L. Facing Covid-19 in Italy - Ethics, Logistics, and Therapeutics on the Epidemic's Front Line. N Engl J Med 2020;382:1873-5.

12. Carvalho ACC, Kritski A. Learning from the Italian experience in coping with COVID-19. Rev Soc Bras Med Trop 2020;53:e20200199.

13. Pisano GP, Sadun R, Zanini M. Lessons from Italy's response to coronavirus. Harvard Business Review; 2020.

14. European Commission. 2020 European semester: Country report-Italy. 2020.

15. Sanfelici M. The Italian Response to the COVID-19 Crisis: Lessons Learned and Future Direction in Social Development. The International Journal of Community and Social Development 2020;2:191-210.

16. Presidential Task Force. National COVID-19 pandemic multi-sectoral response plan; 2020.

17. Amzat J, Aminu K, Kolo VI, et al. Coronavirus outbreak in Nigeria: Burden and socio-medical response during the first 100 days. Int J Infect Dis. 2020;98:218-24.

18. Shuaib F, Gunnala R, Musa EO, et al. Ebola Virus Disease Outbreak - Nigeria, July-September 2014. MMWR Morb Mortal Wkly Rep 2014;63:867-72.

19. Adediran I. Lagos Begins Telemedicine for CoronavirusUnrelated Health Issues. AllAfrica.com. April 22, 2020.

20. Lee M, You M. Psychological and Behavioral Responses in South Korea During the Early Stages of Coronavirus Disease 2019 (COVID-19). Int J Environ Res Public Health 2020;17:2977.

21. Moon MJ. Fighting COVID-19 with Agility, Transparency, and Participation: Wicked Policy Problems and New Governance Challenges. Public Adm Rev 2020;80:651-6.

22. Park S, Choi GJ, Ko H. Information Technology-Based Tracing Strategy in Response to COVID-19 in South Korea-Privacy Controversies. JAMA 2020;323:2129-30.

23. John Hopkins University. COVID-19 Map. John Hopkins Coronavirus Resource Center. 2020. Available online: https://coronavirus.jhu.edu/map.html

24. Chu KM, Smith M, Steyn E, et al. Changes in surgical practice in 85 South African hospitals during COVID-19 hard lockdown. S Afr Med J 2020;110:916-9.
25. Miller GA, Buck C, Kang C, et al. COVID-19 in SeattleEarly lessons learned. J Am Coll Emerg Physicians Open 2020;1:85-91.

26. Schiller DS, Fulman M, Champagne J, et al. COVID-19 pandemic planning, response, and lessons learned at a community hospital. Am J Health Syst Pharm 2020. doi: 10.1093/ajhp/zxaa298.

27. Burnett GW, Katz D, Park CH, et al. Managing COVID-19 from the epicenter: adaptations and suggestions based on experience. J Anesth 2021;35:366-73.

28. Auerbach A, O'Leary KJ, Greysen SR, et al. Hospital Ward Adaptation During the COVID-19 Pandemic: A National Survey of Academic Medical Centers. J Hosp Med 2020;15:483-8.

29. Jazieh AR, Chan S, Curigliano G, et al. Delivering Cancer Care During the COVID-19 Pandemic: Recommendations and Lessons Learned from ASCO Global Webinars. JCO Glob Oncol 2020;6:1461-71.

30. Rutala W, Weber DJ. Disinfection and Sterilization Guideline. CDC Website. May 2020.

31. Ivers LC, Walton DA. COVID-19: Global Health Equity in Pandemic Response. Am J Trop Med Hyg 2020;102:1149-50.

32. Lingam L, Suresh Sapkal R. COVID-19, Physical Distancing and Social Inequalities: Are We all Really in this Together? The International Journal of Community and Social Development 2020;2:173-90.

33. Wright M, Versteeg R, Hall J. General practice's early response to the COVID-19 pandemic. Aust Health Rev 2020;44:733-6.

34. Elshtain JB. The Jane Adams reader. New York, NY: Basic Books. 2002.

35. Harrington D, Dolgoff R. Hierarchies of Ethical Principles for Ethical Decision Making in Social Work. Ethics Soc Welf 2008;2:183-96.

36. Kerson TS. Sixty years ago: hospital social work in 1918. Soc Work Health Care 1979;4:331-43.

37. National Association of Social Workers. (n.d.). Code of Ethics. Available online: https://www.socialworkers.org/ About/Ethics/Code-of-Ethics

38. Tims M. Jane Addams of Hull House, 1860-1935: A Centenary Study. Macmillan; 1961.

doi: 10.21037/jhmhp-21-19

Cite this article as: Muskopf J, Sudan N, Verdooner E, Nair M. Organizational learning-COVID-19 experience: innovative global practices for improving patient care in crisis response. J Hosp Manag Health Policy 202 1;5:20. 